\title{
APPLICATION OF MATHEMATICAL MODELLING IN RAINFALL FORCAST: A CSAE STUDY IN SGS. SARAWAK BASIN
}

\author{
Beatrice C.B ${ }^{1}$, Nasser R. Afshar ${ }^{2}$, Selaman O. $S^{3}$, H.Fahmi ${ }^{4}$ \\ ${ }^{1}$ Lecturer, Faculty of Civil Engineering, Universiti Teknologi MARA, Sarawak, Malaysia \\ ${ }^{2}$ Associate Professor, Department of Civil Engineering, Universiti Malaysia Sarawak, Sarawak, Malaysia \\ ${ }^{3}$ Senior Lecturer, Department of Civil Engineering, Universiti Malaysia Sarawak, Sarawak, Malaysia \\ ${ }^{4}$ Deputy, Water and Wastewater Planning Bureau, Ministry of Energy, Tehran, Iran
}

\begin{abstract}
Malaysia receives rainfall from $2000 \mathrm{~mm}$ to $4000 \mathrm{~mm}$ annually where it is greatly influenced by two monsoon periods in November to March and May to September. The state of Sarawak is well known for its long and wide rivers. Numerous activities such as commercial, industrial and residential can always be found in the vicinity of the rivers. The activities have started since decades ago and still continue to grow and spatially expanding through times providing incomes ranging from small farmers to the largest corporations. Unfortunately, these areas are expected to experience frequent flood events as well as possible receding water level in rivers based on the findings of previous studies. If the projections are accurate, the productivity of these activities will be reduced, hence, in a longer term may affect the economy of the state as whole as well. Therefore, there is an urgent need for existing knowledge on rainfall behavior to be revised as effects of climate change with the intention that the state can fully utilize the favorable conditions and make scientific based decisions in the future.

Recent study reveals that the Fourier series (FS), has the ability to simulate long-term rainfall up to 300 years is viewed as an important finding in the study of rainfall forecast. Long-term rainfall forecasting is viewed to be beneficial to the state of Sarawak in its future planning in various sectors such as water supply, flood mitigation, river transportation as well as agriculture. The main goal of the study is to apply a mathematical modeling in rainfall forecasting for the Sungai Sarawak basin. Data from eight rain gauge stations was analyzed and prepared for missing data, consistency check and adequacy of number of stations. Simple statistical analysis was conducted on the data such as maximum, minimum, mean and standard deviation. 27 years of annual rainfall data were simulated with the Fourier Series equation using spreadsheet. Hence, the result was compared with the Fitting N-term Harmonic Series. The model result reveals that the Fourier Series has the ability to simulate the observed data by being able to describe the rainfall pattern and there is a reasonable relationship between the simulation and observed data with $p$-value of 0.93 .
\end{abstract}

Keywords: Fourier series, Mathematical modeling, N-term Harmonic Series, Rainfall forecast, long-term)

\section{INTRODUCTION}

Recent regional climate projects that the mean sea level, temperature and rainfall variability in all regions will increase in the future. Sammathuria [1] have used Regional Hydro - Climate Model for Peninsular Malaysia (RHCM) and Providing Regional Climater for Impact Studies (PRECIS) to project the annual precipitation anomaly, December-January-February (DJF) seasonal precipitation anomaly and annual rain days projections for the year 2000 to 2099. The significant interdecadal variation detected in all simulations suggested that there would be a long-term extended dry spells. Sarawak is predicted to experience negative annual precipitation for forty years. Therefore, there is an urgent need for existing knowledge on rainfall behavior to be revised as effects of climate change with the intention that the state can fully utilize the favorable conditions and make scientific based decisions in the future. Further study in rainfall forecasting focusing on the state of Sarawak is crucial to improve the estimation accuracy for long-term rainfall prediction for the purpose of planning and management in various sectors where rain is considered as a major driving factor such as agriculture and water resources. Recent study by Rostam Afshar and Fahmi [2] reveals the ability of Fourier Series to simulate long-term rainfall up to 300 years is viewed as an important finding in the study of rainfall forecast. For this reason, the main goal of the study is to simulate rainfall using Fourier Series for Sarawak River Basin hence verify the simulation result using statistical tests.

Studies on rainfall forecast are observed to be more active on conceptual models that may be due to the reason such models do not need to consider the physics of the rainfall processes and only requires the historical data as input [3]. However, the inability of the model to predict any changes that did not occur in the past has limited its pattern recognition method [4]. Maier and Dandy[5] stated that since the conventional statistical approach is difficult to be applied in real life, practitioners are found to be using ANN modeling in their studies. ANN is limited to short-term forecasting where it is found to be a very reliable tool in a flood warning system. Nevertheless, there is a shortcoming 
in its application where "there is a tendency among users to throw a problem blindly at a neural network in the hope that it will formulate an acceptable solution [6]. The introduction of ANN into hydrologic modeling has been more than welcome because it allows any researcher to conduct rainfall modeling study regardless of his area of expertise.

A review done by Gooijer and Hyndman [7] for Elsevier, reveals that from the year 1985 to 2005 there were active research activities on time series forecasting whereby onethird of the papers published were related to models such as Autoregressive Integrated Moving Average (ARIMA) and Seasonal Autoregressive Integrated Moving Average (SARIMA). Regardless of the type of model applied, time series plays an important role in hydrological modeling where all literatures in this study have incorporated time series as part of their data analysis. Time series is significant in rainfall characterization and with statistical analysis; it is viewed that the results of models will be further improved Wang et al. [8], Soon and Sheau [9], Tarpanelli et al. [10] and $\mathrm{Wu}$ and Chau [11]. Time series is favorable as a part in a model structure to describe data using summary statistics and graphical methods, to find suitable statistical models to describe the data generating process, to estimate the future values of a series and controlling a given process Radhakrish [12]. In addition, it has the ability to capture long-term changes hence producing long term forecasting. This can be seen as an approach to overcome the limitation of most models.

Fourier Series (FS) is an infinite expansion of a function of sins and cosines whereby in physics and engineering, such expansion is useful as functions can be easily manipulated especially for discontinuous functions. FS is widely applied in fields such as electronics, quantum mechanics, and electrodynamics.

Literature review reveals that FS is normally used as an analysis tool in any hydrologic concerning periodicity. Anderson et al. [13] used FS as a tool to reduce parameters in PARMA models for river flow study which gave positive result whereby a synthetic flow was able to be produced with all statistical data features. Studies indicated that FS is used as part of the analysis but not as a hydrologic model.

Suhaila and Jemain [14] conducted a study to model quantitative daily rainfall by using smooth technique in Peninsular Malaysia. FS was used as the approach and the performance of FS in describing seasonal behavior was measured with its deviance. The study concluded that smoothing techniques with FS approach was able to describe the rainfall pattern based on mean rainfall per rainy day despite the limitation on the probability of rainy events and the effect of preceding day which could have been dry or wet.

Yusof et al. [15] used Neyman Scott Rectangular Pulse Model (NSRP) for rainfall simulation. However, the model is limited to stationary variables in addition; the model also requires an approximate of 84 parameters in a year.
Therefore, FS is used to present the seasonal pattern with smaller number of coefficients to be estimated. The study stated that FS is able to capture the statistical characteristics of the rainfall as well as economical alternative to describe rainfall.

\section{MATERIAL AND METHOD}

\subsection{Fourier Series}

$$
\begin{aligned}
& f(x)=a_{0}+\sum_{n=1}^{\infty}\left(a_{n} \cos \frac{n \pi x}{L}+b_{n} \sin \frac{n \pi x}{L}\right) \\
& a_{n}=\frac{1}{L} \int_{-L}^{L} f(x) \cos \left(\frac{n \pi x}{L}\right) d x \\
& b_{n}=\frac{1}{L} \int_{-L}^{L} f(x) \sin \left(\frac{n \pi x}{L}\right) d x \\
& a_{0}=\frac{1}{L} \int_{-L}^{L} f(x) d x
\end{aligned}
$$

\subsection{Modelling}

Daily rainfall data of fifteen rain gauge stations was obtained from the Kota Samarahan Department of Irrigation \& Drainage (DID) i.e. Padawan, Sembam, Bau, Kuching Airport, Matang, Kuching Third Mile, Sungai China and Rampangi.

The data was screened and checked for adequacy of number of stations. Hence, estimation of missing data was determined and Double Mass Curve was adopted to test for the consistency of record where five stations i.e. Kuching Third Mile, Bau, Kuching Airport, Rampangi and Matang were selected as the base stations to check the consistency of Padawan, Sungai China and Sembam stations records. The point rainfall data was then converted to mean areal rainfall by using Thiessen-Polygon Method.

The annual rainfall data was analyzed to determine a function that represents the data based on the mean value as well as the corresponding coefficients. Model simulation was done using spreadsheet for $\mathrm{n}=0,1,2,3$ and 4 . Observed and simulation model were compared from the year 2003 to 2011 (Figure 1). The simulation result was evaluated for $\mathrm{x}^{2}$ and RMS and compared with the observed data as well as simulation result using Fitting N-term Harmonic Series Rostam Afshar and Fahmi [2].

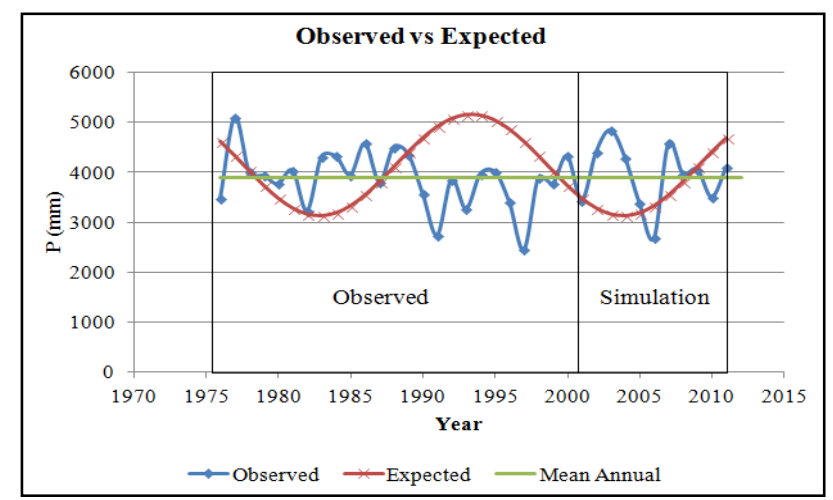

Fig -1: Simulation output for $2003-2011$ 
Figure 1 shows that although, the simulation was unable to accurately match the observed data, however, the model had succeeded in simulating the pattern of the observed rainfall where the simulated data was found to be closely scattered near to the mean value. Refinement in the analysis of data such as using moving average will further enhance the ability of the model to describe the pattern of the rainfall. Sensitivity analysis was conducted using three different numbers of harmonic i.e. 2, 3 and 4 (Table 1). $x^{2}$ was tested for two tailed test with $\alpha$ of 5\%. Results of statistics tests indicate that the model has the ability to simulate the rainfall for the study area with $x^{2}$ of 2.95 and a $p$-value of 0.93 . Executing the model at $n$ equals to 2 and 4 were rejected due to the lack of evidence that the relationship between observed and simulation existed, $x^{2} 2.68$ and 1.02 respectively. In terms of relationship, $n=3$ showed the most reasonable relationship among all three numbers of harmonic, however, refinement of modelling is required based on the value of RMSE i.e. $1133 \mathrm{~mm}$.

Table -1: RMSE and $x^{2}$ for $n=2,3$ and 4
\begin{tabular}{|l|l|l|}
\hline $\mathrm{n}$ & RMSE & $\chi^{2}$ \\
\hline 2 & 1054 & 2.68 \\
\hline 3 & 1134 & 2.98 \\
\hline 4 & 1070 & 1.02 \\
\hline
\end{tabular}

Comparing the observed rainfall to Fitting N-term Harmonic Series, it is predicted that in the future, the observed rainfall might follow the trend of the mean rainfall. The $x^{2}$ and RMSE attained were 6.034 and 9.821 respectively. The result from Fitting N-term Harmonic Series (Table 2) showed better relationship and less error when compared to the simulation executed with spreadsheet. This is due to flexibility of the application to select wide range of average number of harmonic series and harmonic number as well as more refine data input i.e. monthly data compared to annual data.

Table 2: Observed, Simulation, Harmonic Series result for

\begin{tabular}{|l|l|l|l|l|l|}
\hline $\begin{array}{l}\text { Observe } \\
\mathrm{d}\end{array}$ & $\begin{array}{l}\text { Simulati } \\
\text { on }\end{array}$ & Max. & Min. & $\begin{array}{l}\text { First } \\
\text { run }\end{array}$ & Mean \\
\hline 3821 & 4347 & 4062 & 3500 & 3772 & 3779 \\
\hline
\end{tabular}

\section{CONCLUSION}

The model was able to simulate the observed rainfall pattern with reasonable accuracy with the help of suitable computer program. This is proven by the improvement of RMSE and $x^{2}$ values with the application of Fitting $\mathrm{N}$-term Harmonic Series. It is viewed that the result of the study was greatly influenced by the selection of approach in data processing. Data processing is crucial in rainfall modelling to smooth the noise in the data. For easier simulation, the stochastic component of the rainfall must be properly removed to simulate the deterministic component of rain. The Double
Mass Curve used in the study is considered to be insufficient.

The goal and objectives of the study have been achieved where the simulation results showed a reasonable relationship between observed and simulation data. Therefore, FS has the potential to be further improved for the purpose of long-term rainfall forecast. Nonetheless, refinement data analysis and selection of suitable data processing tool and computer program are required for future study.

\section{ACKNOWLEDGEMENTS}

The authors would like to thank the Department of Civil Engineering UNIMAS and the Faculty of Civil Engineering UiTM Sarawak for their continuous support and kindness; as well as the Department of Irrigation and Drainage Sarawak for providing the required hydrology data as well as technical knowledge.

\section{REFERENCES}

[1]. Sammathuria, M. K. Kwok, L. L. \& Wan Hassan, W. A. (2010). Extreme Climate Change Scenarios over Malaysia for $2001-2099$. [Online] Available at: http://www.met.gov.my/index.php?option=com_content\&ta sk=view\&id=2563\&Itemid $=1947$

[2]. Rostam Afshar, N. \& Fahmi, H. (2012). Rainfall Forecasting Using Fourier Series. Journal of Civil Engineering \& Architecture. 16. 44.

[3]. Luk, K. C., Ball, J. E. \& Sharma, A. (2001). An Application of Artificial Neural Networks For Rainfall Forecasting. Mathematical and Computer Modeling. 33. 683-693.

[4]. Wei, C. H. (2008). Rainfall Forecasting By Technological Machine Models. Applied Mathematics and Computation, 200. 41-57.

[5]. Maier, H. R. \& Dandy, G. C. (2000). Neural Networks for Prediction and Forecasting of Water Resources Variables: A Review of Modeling Issues and Applications. Environmental Modeling \& Software. 15. 101-124.

[6]. Flood, I. \& Kartam, N. (1994). Neural Networks in Civil Engineering. I: Principles and understanding. Journal of Computing in Civil Engineering. 8. 131-148.

[7]. Gooijer, J. G. \& Hyndman, R. J. (2006). 25 Years of Time Series Forecasting. International Journal of Forecasting. 22. 443-473.

[8]. Wang, S., Feng, J. \& Liu, G. (2011). Application of Seasonal Time Series Model in the Precipitation Forecast. Mathematical and Computer Modeling. [Online] Available at: doi:10.1016/j.mcm.2011.10.034.

[9]. Soon, K. T. \& Sheau, Y. S. (1997). Synthetic Generation of Tropical Rainfall Time Series Using an Event-Based Method. Journal of Hydraulic Engineering. 2, 83-89.

[10]. Tarpanelli, A., Franchini, M., Brocca, L., Camici, S., Melone, F. \& Moramarco, T. (2012). A Simple Approach For Stochastic Generation Of Spatial Rainfall Patterns. Journal of Hydrology. 472-473. 63-76. 
[11]. Wu, C. L. \& Chau, K. W. (2012). Prediction of Rainfall Time Series Using Modular Soft Computing Methods. Engineering Applications of Artificial Intelligence. [Online] Avilabale at: http://dx.doi.org/10.1016/j.engappai.2012.05.023

[12]. Radhakrishnan, P. \& Dinesh, S. (2006). An Alternative Approach to Characterize Time Series Data: Case Study On Malaysian Rainfall Data. Chaos Solitons \& Fractals. 27. 511-518.

[13]. Anderson, P. L., Tesfaye, Y. G. \& Meerschaert. (2007). Fourier-PARMA Models and Their Application to River Flows. Journal of Hydrologic Engineerin. 12. 462 472.

[14]. Suhaila, J. \& Jemain, A. A. (2009). A Comparison of the Rainfall Patterns Between Stations on the East and the West Coasts of Peninsular Malaysia using the Smoothing Model of Rainfall Amounts. Meteorological Applications. 16. $391-401$.

[15]. Yusof, F., Abas, N. \& Daud, Z. M. (2008). Fourier Series in a Neyman Scott Rectangular Pulse Model. Matematika. 24-2.243-257.

\section{BIOGRAPHIES}

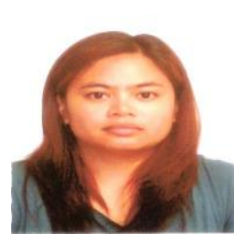

Beatrice Bidaun graduated in Master of Engineering (Civil), UNIMAS and currently working as a Lecturer with UiTM Sarawak under the Faculty of Civil Engineering

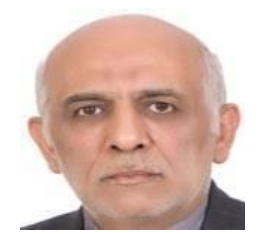

Associate Professor Dr. Nasser is specialized in Hydraulic Structures. He has in his credit teaching, research, industrial, and managerial within the government experiences of more than thirty years in the field of Hydraulic structures, Hydropower, sedimentation, Hydrology, flood control, Water Resources Planning and Value Engineering.

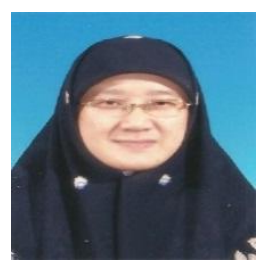

Dr. Selaman, O. S. is a Senior Lecturer in the Department of Civil Engineering at the Faculty of Engineering in Universiti Malaysia Sarawak (UNIMAS). Before joining the University, she had been working as a Civil Engineer for five years at a local consulting firm. Her area of specialization is in Engineering Hydrology, particularly in watershed characteristics, rainfall analysis, flood frequency analysis, and peak discharge estimation at small scale watershed.

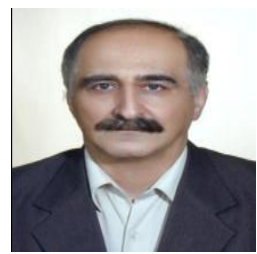

Dr. H. Fahmi has been appointed as senior lecturer in the Department of Science and Research in University of Tehran. At present he is Deputy of Water and Wastewater Planning Bureau of Ministry of Energy in Iran. He has experiences of teaching and research more than thirty years in the field of water resources engineering and management, Hydrology and flood mitigation. 